\title{
Ateşleyici Liderlik Ölçeği (ALÖ) Geliştirme Çalışması*
}

\author{
Sparking Leadership Scale (SLS) Development and Validation
}

Elif BİLGINOĞLU1

Uğur YOZGAT22

Geliş tarihi: 29.03.2019, Kabul tarihi: 06.12.2019, Basım tarihi: 10.05.2020

\section{Öz}

Liderlik, yıllardır farklı açılardan incelenmektedir. Son yıllarda yapılan tüm çalışmalar, liderin vizyonu belirlemenin yanı sıra, çalışanlara ilham ve enerji de verebilmesi gerektiği konusunda birleşmektedirler. Araştırmalar, günümüzde çalışanların büyük bir kısmının işlerine angaje olmadıklarını (unengaged) ortaya koymaktadır. Hızla değişen iş dünyasında başarılı olabilmek için, örgütlerin, çalışanlarının işe angaje olmalarından (employee engagement) çok daha fazlasına ihtiyaçları vardır. Artık örgütlerde asıl önemli olan tutkulu çalışanlara sahip olmaktır. Bu noktada liderlerin karşılaştığ zorluk, çalışanların ne şekilde işe angaje edilecekleri değil; tutkularının nasıl ateşleneceğidir. İşe angaje olmayan çalışanların tutkusunu ateşlemenin anahtarı ateşleyici liderlik olduğu için, bu konunun detaylı bir şekilde araştırılması önem taşımaktadır. Bu araştırma, ateşleyici liderlik üzerine teorik bir çerçeve sunuyor olması yanı sıra, Ateşleyici Liderlik Ölçeği (ALÖ)'ni geliştirme çalışmasını da içermektedir.

Anahtar Kelimeler: Ateşleyici Liderlik, İse Angaje Olma, Isse Angaje Olmayan Calışanlar, İsyerinde Tutku, Tutkulu Örgütler

JEL Kodlar1: M00, M12, O15

\begin{abstract}
Today the challenge facing the leaders is not how to engage employees; it is how to keep the fires of passion burning. Nevertheless, most studies neither link the two constructs nor explain how the leaders may make an influence on the disengaged employees to turn them into a passionate workforce. The aim of this paper is to shed light on how sparking leaders ignite passion into the disengaged employees and translate them into a passionate workforce. This paper introduces a theoretical framework for sparking leadership and develops "Sparking Leadership Scale (SLS)" to measure it. The proposed model on sparking leaders, unengaged employees and passionate organizations relationship provides a conceptual framework in an area where little prior research that relies on anecdotal evidence has been done.
\end{abstract}

\footnotetext{
*Bu çalsşma 27. Ulusal Yönetim ve Organizasyon Kongresi'nde (2019) sunulan sözel bildirinin genişletilmiş ve güncellenmiş halidir.

1 İstanbul, Türkiye, Dr.

elifb@ada.net.tr

https://orcid.org/0000-0003-1481-0170

2 Nişantaşı Üniversitesi, Prof. Dr.

ugur.yozgat@nisantasi.edu.tr

https://orcid.org/0000-0001-9893-3551
} 
Keywords: Sparking leadership, engagement at work, disengaged employees, passion at work, passionate organizations

JEL Codes: M00, M12, O15

\section{Giriş}

Stratejik yönetim bir örgütü daha ileri taşıyan yolları araştırdı̆̆1 için, liderlik, örgütlerde amaç ve strateji geliştirilebilmesinin hayati bir bileşenini oluşturmaktadır (Hannagan, 2002: 164). Üst yönetim teorisi (Upper echelons theory) üst düzey yöneticilerin özel bilgi, deneyim, değer ve tercihlerinin, çevreye ilişkin değerlendirmelerini ve aldıkları stratejik kararları etkilemekte olduğunu ileri sürmektedir (Hambrick ve Mason, 1984). Zaman, dikkat ve öz farkındalığa odaklanarak adanmışlık yoluyla mükemmelleştirilen bir beceri olan liderlik, değişen çevrenin zorluklarıyla mücadele etmeye çalışan örgütlerde özellikle önem taşımaktadır. Liderler, olabilecekleri en iyi lider olmak için zaman ve çaba harcamalıdırlar (Byham ve Wellins, 2015: 243; Daft, 2003: 532).

Liderliğin ne olduğu ve kimlerce ustalıkla uygulanabileceği konusundaki görüşler yıllar içinde önemli ölçüde değişmiştir. Günümüzde, bir örgütte kalıcı bir değişime öncülük edecek bir değişime sebep olmak her zamankinden daha karmaşık hale gelmiştir. 21. yüzyıl hem çalışanlar hem de liderler için birçok yeni zorluğu beraberinde getirdiği için, bu kişiler son derece hızlı bir şekilde değişen dünyamızda bilişsel esneklik ve farklı düşünme konularında kendilerini geliştirmelidirler. Tipik liderlik araştırmalarından (Hunter, Bedell-Avers ve Mumford, 2007) farklı olan yeni liderlik teorileri, liderliği son derece karmaşık olarak görmektedirler (Bennis ve Nanus, 2005; Gleeson, 2017; Greenberg, 2012; Riggio, 2010). Bu teoriler, liderliğin duygusal yönünü vurgulamakta ve ruh, öz, inanç ve umudun liderliğin tam kalbinde yer aldığını iddia etmektedirler (Bolman ve Deal, 2011: 10). Bu teoriler aynı zamanda 21. yüzyll liderlerinin her durumda en iyi sonuca ulaşabilme yeteneğine sahip olmaları gerektiğini de belirtmektedirler. Lider cesur olmalı, mevcut duruma meydan okumaktan korkmamalı, daha da iyisine ulaşabilmek için sınırları zorlamalı ve aynı zamanda çalışanların tüm potansiyellerini açığa çıkartarak, onları nasıl çalıştıkları örgütler için en faydalı olacakları hale getireceğini bilmelidir (Llopis, 2014).

21. yüzyılda ayakta kalabilmek için kuruluşlar işgücünün enerjisine ve bağlilığına güveniyorlar (Gleeson, 2017). Ancak yapılan araştırmalar, dünyada çalışanların işe angaje olmamaları hakkında bir kriz yaşanmakta olduğunu ve bu durumun küresel ekonomiye ciddi ve potansiyel olarak kalıc1 yansımaları olacağını ortaya koymaktadır (Mann ve Harter, 2016). Bu konu, liderler üzerinde yetenekli çalışanları elde tutma ve onlanı iş geliştirme hedeflerini gerçekleştirme konusunda cesaretlendirmek için yeni yollar 
geliştirme konusunda baskı yaratmaktadır (Aselstine ve Alletson, 2006). Bu yüzden günümüz rekabetçi örgütsel ortamı ve hızla gelişen iş dünyasında örgütler, çalışanlarını işe angaje edecek güçlü liderler geliştirmelidirler (Global Human Capital Trends, 2015). Liderlik aslında her zaman önemli bir konu olmuş olmakla birlikte, modern dünyada hiçbir zaman şimdi olduğundan daha önemli olmamıştır (Bennis, 2007: 2).

Liderlik teorisi gelişmiş ve etkili liderlik kavramları değişmiştir. Çağdaş liderlik teorisi geleneksel liderlik teorisine göre farkll11k göstermektedir (Komives ve Dugan, 2010: 113; McShane ve Glinow, 2005). Bu yüzden günümüzde yapılan çalışmalar, liderliği algılamanın farklı yollarını öğrenmeye başlamalıdır. Araştırmacılar, evrensel liderliğin tanımlanması olarak kabul edilen "bireyin, üye olduğu kuruluşun verimliliğine ve başarısına katkıda bulunmak için başkalarını etkileme, motive etme ve başkalarına katkıda bulunma yeteneğı'" tanımı üzerinde fikir birliğine varmışlardır (House, Javidan ve Dorfman, 2001: 494). Bu, liderliğin bireylerin, grupların ve örgütlerin gelişmesini, olabileceklerinin en iyisi olmalarını ve beklentileri çarpıcı biçimde aşmalarını sağladı̆̆ı anlamına gelmektedir (DeRue ve Workman, 2012).

İşe angaje olmama çalışanlar arasında yaygın olup, işe angaje olmaktan daha kapsamlı bir yap1 olan (The Ken Blanchard Companies, 2009: 3) ve daha derin ve uzun vadeli olarak değerlendirilen tutkunun işe angaje olmaktan daha önemli (Denning, 2014; Robins, 2017) hatta kritik önemde olduğu düşünülse de; pek çok çalışma, bu iki yapıyı birbirleriyle bağıntılı olarak ele almamakta ve liderlerin, işe angaje olmayan çalışanlar üzerinde ne şekilde bir etki yaratarak onlardan tutkulu bir işgücü yaratacaklarını açıklamamaktadır. Bu çalışmanın amacı, ateşleyici liderlerin işe angaje olmayan çalışanların tutkularını nasıl ateşleyerek onları tutkulu bir işgücüne çevirdikleri konusuna 1şık tutmaktır.

\section{Kavramsal Çerçeve}

\section{1. İşe Angaje Olmuş Çalışanlar ve Tutkulu Örgütler için Ateşleyici Liderlik}

Motivasyonunu kaybetmiş çalşsanları motive etmenin belirli yolları olmamasına rağmen, bir liderin bu konuda şansını artırabilmek için atabileceği birtakım adımlar söz konusudur. Yönetim, çalışanları işi yapmak ister hale gelecekleri şekilde yönlendirmelidir. Lider öncelikle, çalışanlarını birer birey olarak tanımalı ve böylece potansiyellerini ortaya koyacakları şekilde çalışmıyor olmalarının nedenlerini ve yetenekleri ile gerçekleştirdikleri arasındaki farkı yaratanın ne olduğunu görebilmelidir. Bir lider kişisel ve takım dinamiklerinin tamamen farkında olmalıdır. Bir lider, kişilerin ilgi alanlarını ateşleyen doğru eşleşmelerin bulunmasıyla, son derece şaşırtıcı ve olağanüstü sonuçlar elde edilebileceğinin bilincinde olduğu için, çalsşanların 
ilgisini çeken görevler bulmalıdır. Ve son olarak bir lider, kendi beklentilerini çalışanlarına açıkça ifade etmelidir (Lipman, 2014). Malone (2004), çalışanların ateşlerinin tam olarak nerede yanıyor olduğunu tanımlamak için bir liderin öncelikle bir takımın üyelerini yönlendiren çalısma tutkularını tanımlaması ve daha sonra onları bu alanlarda ilerlemeleri için cesaretlendirmesi gerektiğini belirtmektedir. Bir lider, çalışanların neleri yapmayı sevip, neleri yapmayı sevmediklerini, en iyi oldukları konuların neler olduğunu ve hangi konularda en büyük örgütsel etkiye sahip olabileceklerini ortaya çıkarmalıdır. Bireysel ateşleri işte tam da bu noktalarda yanmakta olduğu için, onları bu alanlarda inisiyatif almaları konusunda teşvik ederek güçlü oldukları alanlara yönlenmelerini sağlamalıdır.

Lider, çalışanların işe angaje olmaktan uzaklaştıklarını fark ettiğinde, onları işe angaje etmek ve bu durumu koruyabilmek konusunda aktif bir rol üstlenmelidir. Çalışanlarla sürekli iletişimde kalabilmeli ve bu şekilde onların içlerindeki kıvılcımı yeniden alevlendirmelidir (Brown, 2016; Whitehurst, 2015).

Lider, çalışanlara, anlamlı bir çalışma sunarak ve pozitif bir çalışma ortamı yaratarak, takdir edildiklerini ve gelişmeleri konusunda cesaretlendirildiklerini fark etmelerini sağlayabilir ve böylece onları işe angaje edebilir. Bu üç unsur, kişiler için gerçekten önemli olan şeylerin ve işleriyle ilgili nasıl hissettiklerinin merkezinde yer almaktadır (Byham ve Wellins, 2015: 137-138).

Örgütler için çalışanların içindeki ateşi yakmanın ve onları işlerine tekrar angaje etmenin bir başka yolu da onları neyin motive ettiğini anlamak, onları rahatlatarak, güçlü yanlarını vurgulamak ve liderleri dikkatlice seçmekten geçmektedir (Reisinger, 2015). Daha önce yapılan çalışmalarda liderliğin çalışanların işe angaje olmasındaki etkisi ortaya koyulmaktadır (García-Sierra, Fernández-Castro ve Martínez-Zaragoza, 2016; Salanova, Lorente, Chambel ve Martínez, 2011).

İş tutkusu, çalışanların işe angaje olmayı deneyimleyebileceği psikolojik bir süreçtir (Trépanier, Fernet, Austin, Forest ve Vallerand, 2014: 357). Colan (2014), tutkulu performans konusundaki anahtarın, çalşsanların kalpleri ve zihinlerinde bulunduğunu ve temel insan ihtiyaçlarının da burada karşılandığını belirtmektedir. Ana formül, kişilerin ihtiyaçlarının karşılamasıdır. Daha sonra işe angaje olurlar ve en üst düzeyde performans sergilerler. Aksi takdirde, işe angaje olmazlar ve bu da hüsrana uğradıkları, kontrolden çıktıkları, odaklarını kaybettikleri ve bağlantılarının koptuğu anlamına gelmektedir. Bu ihtiyaçları karşılamak için, liderler önce onları kabullenmeli ve anlamalıdırlar. Liderler, takımlarına uğruna savaşabilecekleri zorlu bir sebep oluşturmalı, onlarla doğal ve güvenilir bir şekilde bağlantı kurmalı ve onları takdir ettiğini içtenlikle ve özel bir şekilde göstermelidir. 
Ancak çalşsanların tutkusunu ateşlemek isteyen liderlere her şeyden önce, motivasyonlarının, sadece finansal ya da örgütsel başarıya duyulan bir arzudansa, tüm işyerinin moral ve refahını artırmak yönünde gerçek bir arzudan kaynaklanması gerektiği önerilmektedir (Miller, 2017).

Tüm bu yöntemler, tutkularını keşfetmek ve geliştirmek konusunda kişisel düzeyde yol gösterilmesine ve cesaretlendirmeye ihtiyaç duyacakları göz önüne alınarak; tutkularını kaybetmiş olan ya da örgütün temel tutkularını hiç paylaşmamış çalışanlar için geçerli olabilir (Chang, 2001: 185).

Fark1 yaratan şey, tutkudur. Kişiler yaptıkları şey hakkında tutkulu olmak isterler ve çevrelerinde de yaptıkları şey hakkında tutkulu kişiler olmasını isterler (Whitehurst, 2016). Ancak tutkunun sadece içsel bir güç olmadığ1 ve en yüksek düzeye ulaştı̆ı̆ında, etrafa saçılarak başkalarını da kendi ateşinin içine aldığı ve başkalarının kalplerinde bizim için ateşler yaktığı da unutulmamalıdır (Lucas, 1999: 170). Bu ateş hoş ve sıcak olabilir, yavaşça zayıflayabilir, aniden sönebilir ya da birden parlayarak yoluna çıkan her şeyi yok edebilir (Popper, 2001: 43).

\section{Araştırmanın Yöntemi}

Ateşleyici Liderlik Ölçeği (ALÖ) geliştirme çalışmasında üç aşamalı yöntem kullanılmıştır (Churchill, 1979; DeVellis, 2012; Johnson ve Morgan, 2016; Rossiter, 2002). Birinci aşamada ölçek ifadeleri oluşturulmuş, ikinci aşamada ölçek arındırılmış (purification) ve son aşamada ölçek geçerlenmiştir.

\section{1. Ölçek İfadelerinin Oluşturulması}

İfadelerin oluşturulma aşamasında öncelikle kapsamlı yazın taraması yapılmış ve ilişkili bulunan kavramlar üzerinden ifadeler oluşturulmuştur. Ardından elde edilen ifadeler üzerinden yarı yapılandırılmış- mülakat soruları ve planı hazırlanmıştır (Hinkin, 1995; Hinkin, 1998). Mülakatların planlamasında uygun örneklem belirlenmesinde "amaçlı örneklem" yöntemi kullanılmışır (Patton, 2002). Bu teknik genellikle, nitel çalışmalarda kullanılmakta ve çalışma sorularının, çalışmanın uygulanacağı birimin (bireyler, kuruluşlar, örgütler) seçiminde tercih edilen bir yöntemdir (Teddlie ve $\mathrm{Yu}, 2007)$.

$\mathrm{Bu}$ yönteme bağlı kalarak, ifade havuzunun oluşturulması aşamasında bu konuda belli birikimi olan ve daha çok katkı sağlayacağı düşünülen 6 doktora öğrencisi ( 3 erkek 3 kadın) ve 4 insan kaynakları yöneticisi (2 kadın 2 erkek) ile ortalama 30 dakika süren (en kısa 21 ve en uzun 42 dakika) mülakatlar gerçekleştirilmiştir. Katılımcılara ateşleyici liderlik kavramı ile ilgili kısa bilgilendirme yapılmış, bu konudaki görüş ve gözlemleri sorulmuştur. Açık ifadeler elde etmek için katılımcılara sınırlı kaldıkları ifadelerde, alan yazın taraması sonucunda elde edilen mevcut davranış kalıpları çerçevesinde sorular sorulmuş (Ateşleyici liderler "çalışanların performanslarını nasıl 
artırırlar", "sınırlarını zorlamalarını nasıl sağlarlar", "örgüte faydalı olmalarını nasıl sağlarlar", "söylemleri yanında eylemleri nelerdir" ...) ve kendi ifadelerini oluşturmaları sağlanmıştır (İslamoğlu ve Börü, 2007). Bunun sonucunda 32 ifadelik havuz oluşmuştur.

Yazarlar tarafindan tekrar eden, eş anlamlı ve birbirini içeren ifadeler elendikten sonra 23 ifade kalmıştır. Bu ifadeler farklı üniversitelerden alanında uzman farklı 5 akademisyenle (3 profesör ve 2 doçent) tekrar değerlendirilmiş, ölçülmek istenen değişkenin değerlendirilmesinde kullanılabilecek en uygun olduğu düşünülen ifadeler ortak kararla belirlenmiş ve 12 ifade içeren ölçek oluşturulmuştur (Şimşek ve Yıldırım, 2013). Uzmanlar arası tutarlılıkların testi için Cohen Kappa katsayıları hesaplanmış, değerlerin 0,72 ile 0,84 arasında değiştiği tespit edilmiş, kabul sınırlarında olduğu için 12 ifade ile bir sonraki aşamaya geçilmiştir (Landis ve Knoch, 1977).

\section{2. Ölçek Arıtma (Purification)}

12 ifadeli ölçek kolayda örnekleme ile belirlenmiş farklı sektörlerde çalışan 165 çalışan ile ön teste tabi tutulmuştur (Örnek 1). \%10'dan fazla cevaplanmamış ifade içeren anketlerin elenmesinden sonra 148 anket değerlendirmeye alınmıştır (Newman, 2003). Önce ve sonra gelen anketler ortalama ve varyanslar bağlamında karşılaştırılmış, istatistiksel olarak anlamlı bir farklılık belirlenmemiş, yanıtlamama yanlllğ̆ına (non-response bias) ilişkin kanıt bulunmamıştır (Armstrong ve Overton, 1977).

Temel boyutları ve bunlara ilişkin ifadeleri belirlemek için açımlayıcı faktör analizi (AFA) ile verilerin uygunluğu test edilmiştir (Netemeyer, Bearden ve Sharma, 2003; Spector, 1992). Faktör yükleri 0,65'in altında olan 4 ifade silinmiştir (Hair, Black, Babin ve Anderson, 2009).

Tek faktörlü 8 ifadeli ölçeğin öz değeri 6,02'dir ve toplam varyansın $\% 75,31$ 'ini açıklamaktadır, ifadelerin faktör yükleri 0,70 'in üzerindedir ve kabul sınırları içindedir. 8 ifadeden oluşan ölçeğin Cronbach alfa değeri 0,953'dür ve tavsiye edilen eşik değerin üzerindedir (Nunnaly ve Bernstein, 1994). Bileşik (composite) güvenilirlik (CR) değeri $0,91(>0,70)$ ve AVE değeri $0,57(>0,50)$ tavsiye edilen değerlerin üzerinde bulunduğundan yakınsama (convergent) geçerliliği sağlanmıştır (Fornell ve Lackner, 1981).

Tek faktörlü model LISREL ile test edilmiş ve iyi bir uyum gösterdiği bulunmuştur $\left(\chi 2(20)=23,713 ; \chi^{2} / \mathrm{df}=1,19 ; \mathrm{GFI}=0,961\right.$; CFI $=0,966$; SRMR $=0,022 ;$ RMSEA $=0,036$ ).

\section{3. Ölçek Geçerleme (Validation)}

Ölçek geçerleme için geliştirilen ölçeğin alan yazında daha önce geçerlemesi yapılmış benzer ölçeklerle ayrıştı̆ı̆nı gösterilmesi gerekmektedir (DeVellis, 2012). Bu çalışmada Ateşleyici Liderlik Ölçeği 
(ALÖ) ile iki boyutlu İşe Tutkunluk Ölçeği (Vallerand ve diğerleri., 2003) ve beş boyutlu Dönüşümcü Liderlik Ölçeği (Bass ve Avolio, 1997; 2000) kullanılmıştır.

İşe Tutkunluk Ölçeği Vallerand ve diğerleri (2003) tarafindan geliştirilmiştir ve uyumlu tutkunluk (UT) ve takıntılı tutkunluk (TT) olmak üzere iki alt boyuttan oluşmaktadır. Her boyutta 7 ifade yer almaktadır. Ölçeğin Kamanlı (2015) tarafindan yapılan Türkçe geçerlemesi kullanılmıştır. Uyumlu tutkunluğun ölçümünde kullanılan bir örnek ifade "İşim unutulmaz deneyimler yaşamamı sağlar", takıntılı tutkunluk için ise "Ruh halim işimi yapabilmeme bağlıdır" şeklindedir.

Self-report problemini ortadan kaldırmak amacıyla çalışanların tutkunluk düzeylerini bağlı bulundukları yöneticilerinin çalışanların işe tutkunluklarının değerlendirmesine yönelik ifadeler yazarlar tarafından Vallerand ve diğerleri (2003) tarafindan geliştirilen anketin adaptasyonu ve literatürden yararlanarak oluşturulmuştur. Kullanılan ölçek toplam 10 ifadeden oluşmaktadır. Her boyutta 5 ifade yer almaktadır. Uyumlu tutkunluğun ölçümünde kullanılan bir örnek ifade "İşini içselleştirmiştir", takıntılı tutkunluk için ise "Ruh hali işini yapabilmesine bağlıdır" şeklindedir.

Çoklu Liderlik Ölçeği, Bass ve Avolio (1997) tarafindan geliştirilmiştir. Dönüşümcü liderliğin 5 boyutu telkinle güdüleme (TG), atfedilen idealleştirilmiş etki (IEa), davranış olarak idealleştirilmiş etki (İEb), entelektüel uyarım (EU) ve bireysel destek (BD) olarak adlandırılmaktadır. Ölçeğin Yurtkoru (2001) tarafindan yapılan Türkçe geçerlemesi kullanılmıştır.

Ateşleyici Liderlik Ölçeği (ALÖ) 8 sorudan oluşmaktadır (Tablo 1):

Tablo 1. Ateşleyici Liderlik Ölçeği (ALÖ)

Farklı sektörlerde faaliyet gösteren 15 işletmeden anketi yapmak için izin alınarak toplam 423 (işletme başına 16 ile 45 anket arasında) çalışana (Örneklem 2.1) ve çalışanların bir üst yöneticilerine (işletme başına 12 ile 27 arasında, toplam 189) (Örneklem 2.2) dağıtılmıştır. Yöneticiler bağlı 7 ile 35 arasında çalışan bulunmaktadır. Yöneticilerden bağlı çalışanlarının işe tutkunluklarını değerlendirmeleri istenmiş, bu bağlamda kendilerinden çalışanlarının algıladıkları tutkunluklarını ölçmeye yönelik ifadelerin yer aldığı 
anketleri ve demografik özelliklerini ölçmeye yönelik bir anketi doldurması istenmiştir. Çalışanlara dağıtılan anketlerde demografik soruların yanı sıra bir üst kendilerini değerlendirmeleri istenen 14 ifadeli İşe Tutkunluk Ölçeği ve yöneticilerini değerlendirmeleri istenen 8 ifadeli Ateşleyici Liderlik Ölçeği (ALÖ), 20 ifadeli Dönüşümcü Liderlik ölçekleri yer almaktadır.

Çalışan yönetici eşleşmeleri yapıldıktan ve \%10'dan fazla cevaplanmamış ifade içeren anketler silindikten sonra 367 anket kalmıştır. Çalışanların kendi değerlendirmeleri bağlamında hesaplanan tutku değerleriyle, yöneticileri tarafindan yapılan değerlendirmeler arasındaki fark birden fazla olan anketler (96 adet) değerlendirme dışında bırakılmıştır. Böylece self-bias problemi ortadan kaldırlmıştır. Kalan 291 anket LISREL ve SPSS istatistik programlarıyla analiz edilmiştir.

Cevaplayan analize tabi tutulan çalş̧anların \%63,9'u erkek, ortalama yaşlar1 29,35 (en küçük 18 ve en büyük 60) olup, çalısma deneyimleri ortalama 4,99 yıldır ve \%29,4'ü üniversite ve üstü eğitime sahiptir. Yöneticilerin \%85,6's1 erkek, ortalama yaşlar1 34,86 (en küçük 27 ve en büyük 67) olup, çalışma deneyimleri ortalama 7,58 ylldır ve $\% 50,5$ 'i üniversite ve üstü eğitime sahiptir.

Ateşleyici Liderlik Ölçeği doğrulayıcı faktör analizi bağlamında LISREL ile tekrar test edilmiş ve iyi bir uyum gösterdiği bulunmuştur $(\chi 2(20)=$ 46,$635 ; \chi^{2} / \mathrm{df}=2,33 ; \mathrm{GFI}=0,961 ; \mathrm{CFI}=0,981$, SRMR $=0,022 ;$ RMSEA $=0,068)$.

Ateşleyici Liderlik Ölçeğinin Örneklem 1 ve Örneklem 2.1'e ait doğrulayıcı faktör analizi madde yükleri, t-değerleri ve uyum endeksleri değerleri Tablo 2'de verilmiştir.

3 değişkenin (ateşleyici liderlik, tutkunluk ve dönüşümcü liderlik) 8 alt boyutunun (Ateşleyici liderlik, uyumlu tutkunluk, takıntilı tutkunluk, telkinle güdüleme, atfedilen idealleştirilmiş etki, davranış olarak idealleştirilmiş etki, entelektüel uyarım ve bireysel destek) ayrışım (discriminant) geçerliliği LISREL programı ile test edilmiştir. 2 değişken 9 alt boyutlu model iyi bir uyum göstermektedir. $\left(\chi^{2}(791)=1407,684 ; \chi 2 / \mathrm{df}=1,78 ; \mathrm{IFI}=0,937\right.$; CFI $=0,936 ;$ SRMR $=0,044 ;$ RMSEA $=0,049)$. Çeşitli alternatif modeller denenmiş, ancak diğerleri daha düşük uyum göstermiş veya uyum göstermemiştir. Bu bağlamda 2 değişken ve 9 alt boyutun ayrıştığı kabul edilmiştir. 
Tablo 2. Ateşleyici Liderlik Faktör Yükleri, t-Değerleri ve DFA Uyum Endeksleri

\begin{tabular}{|c|c|c|c|c|}
\hline & \multicolumn{2}{|c|}{ Örneklem $1(n=148)$} & \multicolumn{2}{|c|}{ Örneklem $2.1(n=291)$} \\
\hline & Faktör yükü & $t$ değeri & Faktör yükü & $t$ değeri \\
\hline İfade 1 & 0,83 & 12,33 & 0,86 & 18,08 \\
\hline İfade 2 & 0,88 & 13,48 & 0,83 & 17,20 \\
\hline İfade 3 & 0,92 & 14,65 & 0,78 & 15,67 \\
\hline İfade 4 & 0,87 & 13,31 & 0,84 & 17,40 \\
\hline İfade 5 & 0,83 & 12,30 & 0,90 & 19,79 \\
\hline İfade 6 & 0,79 & 11,32 & 0,83 & 17,14 \\
\hline İfade 7 & 0,84 & 12,56 & 0,79 & 16,02 \\
\hline İfade 8 & 0,80 & 11,67 & 0,81 & 16,59 \\
\hline$\chi^{2} / \mathrm{df}$ & \multicolumn{2}{|l|}{1,19} & \multicolumn{2}{|l|}{2,33} \\
\hline GFI & \multicolumn{2}{|c|}{0,961} & \multicolumn{2}{|l|}{0,961} \\
\hline CFI & \multicolumn{2}{|c|}{0,966} & \multicolumn{2}{|l|}{0,981} \\
\hline RMSEA & \multicolumn{2}{|c|}{0,036} & \multicolumn{2}{|l|}{0,068} \\
\hline SRMR & \multicolumn{2}{|c|}{0,022} & \multicolumn{2}{|l|}{0,022} \\
\hline CR & \multicolumn{2}{|c|}{0,953} & \multicolumn{2}{|l|}{0,947} \\
\hline AVE & \multicolumn{2}{|c|}{0.716} & \multicolumn{2}{|l|}{0,680} \\
\hline
\end{tabular}

Temel bileşenler analizi ve Varimax rotasyonu ile doğrulayıc faktör analizi yapılmıştır. Tüm ifadelerin faktör yükleri tavsiye edilen 0,65 değerinin üzerindedir. Kaiser-Meyer-Olkin değeri 0,934 ve Bartlett küresellik testi değeri istatistiki olarak anlamlı bulunmuştur. Bu değerler verilerin açımlayıcı faktör analizine uygunluğunu göstermektedir.

Normal dağılımı test etmek için değişkenlerin basıklık ve çarpıklık değerleri hesaplanmıştır. Basıklık değerleri 0,02 ile -0.91 , çarpıklık değerleri 0,23 ile $-0,54$ arasında değişmektedir ve kabul sınırları içinde yer almaktadır (Tabachnick ve Fidell, 2013).

CR değerleri 0,834 ile 0,965 ve AVE değerleri 0,558 ile 0,711 arasında değişmekte ve tavsiye edilen yakınsama geçerliliği şartlarını sağlamaktadırlar. Alt boyutların Cronbach alfa değerleri 0,88 ile 0,95 değerleri arasında değişmektedir (Tablo 3). 
Tablo 3. Tanımlayıcı İstatistikler, Cronbach Alfa, CR, AVE, Alt Boyutlar Arasındaki Korelasyon, Basıklık ve Çarpıklık Değerleri

\begin{tabular}{|c|c|c|c|c|c|c|c|c|c|c|c|}
\hline Değişken. & Ort & ss & 1 & 2 & 3 & 4 & 5 & 6 & 7 & 8 & 9 \\
\hline 1. $\dot{\mathrm{IE} a}$ & 4,00 & 1,16 & (.93) & & & & & & & & \\
\hline 2. $\quad \dot{I} E b$ & 3,99 & 1,03 & $.50^{* * *}$ & (.88) & & & & & & & \\
\hline 3. TG & 4,07 & 1,11 & $.57^{* * * *}$ & $.60^{* * *}$ & $(.90)$ & & & & & & \\
\hline 4. $\mathrm{EU}$ & 4,04 & 1,07 & $.59^{* * *}$ & $.48^{* * *}$ & $.46^{* * *}$ & $(.90)$ & & & & & \\
\hline 5. $\mathrm{BD}$ & 3,90 & 1,16 & $.56^{* * *}$ & $.45^{* * *}$ & $.49^{* * *}$ & $.51^{* * *}$ & $(.90)$ & & & & \\
\hline 6. DL & 4,00 & 0,87 & $.82^{* * *}$ & $.76^{* * *}$ & $.80^{* * *}$ & $.77^{* * *}$ & $.77^{* * *}$ & $(.94)$ & & & \\
\hline 7. AL & 3,97 & 1,14 & $.54^{* * *}$ & $.56^{* * *}$ & $.60^{* * *}$ & $.57^{* * *}$ & $.57^{* * *}$ & $.72^{* * *}$ & $(.95)$ & & \\
\hline 8. UT & 3,94 & 1,08 & $.35^{* * *}$ & $.32^{* * *}$ & $.35^{* * *}$ & $.33^{* * *}$ & $.31^{* * *}$ & $.42^{* * * *}$ & $.44^{* * * *}$ & $(.91)$ & \\
\hline 9. TT & 4,06 & 1,32 & $.18^{* *}$ & $.15^{* *}$ & $.16^{* *}$ & $.21^{* * *}$ & $.21^{* * *}$ & $.23^{* * *}$ & $.31^{* * *}$ & $.19^{* * *}$ & $(.94)$ \\
\hline CR & & & .857 & .842 & .834 & .847 & .851 & .965 & .913 & .909 & .945 \\
\hline AVE & & & .600 & .572 & .558 & .581 & .589 & .580 & .569 & .587 & .711 \\
\hline $\begin{array}{l}\text { Açılkanan } \\
\text { Varyans \% }\end{array}$ & & & 7,58 & 7,33 & 7,13 & 7,28 & 7,30 & --- & 14,28 & 11,37 & 12,54 \\
\hline Çarpiklık & & & $-0,30$ & $-0,32$ & $-0,49$ & $-0,31$ & $-0,24$ & --- & $-0,27$ & $-0,54$ & $-0,23$ \\
\hline Basıklık & & & $-0,55$ & $-0,23$ & $-0,26$ & $-0,13$ & $-0,27$ & --- & $-0,36$ & 0,02 & $-0,91$ \\
\hline $\begin{array}{l}\dot{I} E a=\text { Atfed } \\
E U=\text { Enter } \\
U T=U \text { Uyuml } \\
C R=\text { Birlesik } \\
\text { Parantez içind } \\
{ }^{*} p<.05,{ }^{* *} p\end{array}$ & $\begin{array}{l}\text { Güveni } \\
\text { ki Cron } \\
<.01 \text {, * }\end{array}$ & $\begin{array}{l}\text { irlik; } A \\
\text { bach alfa } \\
p<.0\end{array}$ & $\begin{array}{l}=1 \text { akem } \\
E=O, \\
\text { deygerleri }\end{array}$ & $\begin{array}{l}\text { th Tutk } \\
\text { talama } \\
\text { osterilmis }\end{array}$ & nluk. & larak I & allestiri & is Etki; & $\begin{array}{l}T G= \\
A L=\end{array}$ & lkinle & $\begin{array}{l}\text { İdüleme; } \\
\text { iderlik; }\end{array}$ \\
\hline
\end{tabular}

Yöneticilerin algılanan ateşleyici liderlikleri ile çalışanların işe karşı uyumlu tutkunluk $\left(0,44^{* * *}\right)$ ve takintilı tutkunlukları $\left(0,31^{* * *}\right)$ arasinda örneklem bağlamında istatistiki olarak anlamlı bir ilişki bulunmuştur. Yöneticilerin alg1lanan dönüşümcü liderliklerinin tüm alt boyutlarılya uyumlu ve takıntılı tutkunluk arasında da istatistiki olarak anlamlı bir ilişki tespit edilmiştir.

Yöneticilerin algılanan ateşleyici liderliklerinin uyumlu ve takıntılı tutkunluk ile ilişkisinin tüm algilanan dönüşümcü liderlik alt boyutlarıyla uyumlu ve takıntılı tutkunluk ile olan ilişkilerinden örneklem bağlamında daha yüksek olduğu tespit edilmiştir.

\section{Sonuç ve Tartışma}

Lider, insanlara büyük bir amaç ve nihayetinde bir vizyonun peşine düşmek konusunda ilham veren kişidir. Yapilan araştırmalar, çalışanların çoğunun işlerini sevmediklerini ortaya koymaktadır (Workforce Purpose Index, 2016). Haftada ortalama 40 saat sevmedikleri bir şeyi yapiyor olan bu kişilerin, tükenmişlik yaşamaları ve işlerine angaje olmayışları son derece 
normaldir. Lider, bir çalş̧anın motivasyonunu kaybettiğine dair işaretleri fark etmeli ve sorun daha da ilerlemeden önce ona ilham vermek konusunda yardımcı olmalıdır. Lider, çalışmak konusunda tutkulu ve enerjik olarak, diğerleri için örnek oluşturmalıdır. Aynı zamanda çalışanlara ilham kaynağı olmalı ve onları yeniden canlandırmak için elinden gelenin en iyisini yapmalidir.

Örgütlerin ihtiyaçları değiştikçe, liderlik kavramı evrim geçirmeye devam etmektedir (Daft, 2003: 514). Liderlik süreci dinamik teoriler arayışındadır (Mostovicz, Kakabadse ve Kakabadse, 2009). Bennis'in de (1998) belirttiği gibi, değişim 21. yüzyıldaki liderlerin karşılaştı̆̆ temel zorluklardan biri olacaktır ve bu, liderlerin liderliklerini yeniden oluşturmak ve yeniden icat etmek zorunda kalacakları anlamına gelmektedir. Geleceğin liderleri, böylesi çalkantılı bir dünyada bir örgütü yönetebilmek için, değişimi kucaklayan bir ortam yaratmayı öğrenmek zorunda kalacaklardır. Bu liderler henüz değişim ihtiyacı onlar için bir tehdit unsuru oluşturmamışen, ne gibi farklı yeterliliklere ihtiyaç duyulduğunu hissedebilecek öz farkındalık ve öz saygiya sahip olmalıdırlar.

İşe angaje olmamanın günümüzdeki gibi yaygın olduğu bir zamanda, büyük liderler en iyi "ateşleyici liderler" olarak tanımlanabilirler. Çünkü bu liderler, çalş̧anları işe angaje olmaya yönlendiren bir örgütsel ortam sağlamanın kendi sorumlulukları olduğunun bilincindedirler. Bu kişiler aynı zamanda bugünün çalışanlarının anlamlı bir işe sahip olmak ve fark yaratan bir şeyin parçası olmak istediklerinin de farkındadırlar. Bu yüzden bu liderler işi ilham verici, zorlayıcı ve anlamlı olacak şekilde düzenlemeleri gerektiğini bilmektedirler. Onlar duygusal enerjilerini, çalışanlar arasındaki tutkuları ve arzuları harekete geçirmek ve çalışanları istenen sonuçlara yönlendirmek için nasıl kullanacaklarını bilmektedirler. Örgütlerinde tutku konusunda ilham vermek onlar için önemli bir önceliktir, bu yüzden çalıştıkları ekipte tutkuyu ateşleyebilmek için çok istekli bir şekilde çalışmaktadırlar. Bir kişinin tutkularının diğerlerinin tutkularını nasıl ateşleyerek, onların hayatlarına enerji getirdiğini bilmektedirler. Bu şekilde tek bir kıvılcımın büyük bir ateş firtınasını tutuşturabileceğini bilmektedirler. Bu yüzden, işe angaje olmayan, ancak bir araya geldikleri zaman ateşi yakılmış bir ekip ve tutkulu bir örgüt oluşturan bir grup insandan oluşan bir ekibi ateşlemektedirler. Ateşleyici liderler, örgütlerini çalışanların zihinleri ve kalplerini işe angaje olmaya odaklayacak şekilde biçimlendirmekte ve tutkulu örgütler inşa etmektedirler. Lucas'n (1999: 170) tutkulu bir örgütün üstün bir rekabet gücünü oluşturduğunu belirttiği gibi, bu liderler sonuçta sürdürülebilir iş sonuçları elde etmek için yaratılan bu enerjiyi kullanmaktadırlar.

Bu çalısmada, ateşleyici liderlik konusunda teorik bir çerçeve sunuluyor olmasının yanı sıra, alan yazında bu değişkeni değerlendirmek için görgül 
olarak onaylanmış herhangi bir ölçüm aracına rastlanmadığı için "Ateşleyici Liderlik Ölçeğı’” geliştirilmektedir.

Ateşleyici liderler, işe angaje olmayan çalsşanlar ve tutkulu örgütler ilişkisi hakkında önerilen bu model, anekdot niteliğindeki kantlara dayanan az sayıda yapilmış geçmiş araştırmaların mevcut olduğu bir alanda kavramsal bir çerçeve sunmaktadır. Daha önce yapılan araştırmalardan elde edilen bilgilere ve yine onlarda yer alan önermelere dayanan bu kavramsal modelin, alan yazına bu noktada katkı yapıyor olması yanı sıra gelecekteki araştırmalara rehberlik edeceğine inanmaktayız.

Yöneticilerin algılanan ateşleyici liderliklerinin uyumlu ve takıntılı tutkunluk ile ilişkisinin tüm algilanan dönüşümcü liderlik alt boyutlarıyla uyumlu ve takıntılı tutkunluk ile olan ilişkilerinden örneklem bağlamında daha yüksek olması ateşleyici liderliğin stratejik önemini göstermektedir.

$\mathrm{Bu}$ nedenle, gelecekte yapılacak olan araştırmalarda, bu çalışmada ileri sürüldüğü gibi ateşleyici liderlerin işe angaje olmayan çalş̧anlardaki ateşi gerçekten tutuşturup tutuşturamayacakları ve bu şekilde tutkulu örgütler inşa edip edemeyeceklerinin görgül olarak ölçülmesi önerilmektedir. 
Kaynakça

Armstrong, J. S. ve Overton, T. S. (1977). Estimating nonresponse bias in mail surveys. Journal of Marketing Research, 14: 396-402.

Aselstine, K. ve Alletson, K. (2006). A New Employment Deal for the 21st Century Workplace. Retrieved at https://iveybusinessjournal.com/publication/a-new-employmentdeal-for-the-21st-century-workplace/ Erişim tarihi 30.09.2019

Bass, B. M. ve Avolio, B. J. (1997). Full Range Leadership Development: Manual for the Multifactor Leadership Questionnaire. Redwood City, CA: Mind Garden.

Bass, B. M. ve Avolio, B. J. (2000). MLQ Multifactor Leadership Questionnaire. Redwood City: Mind Garden.

Bennis, W. (1998). Becoming a leader of leaders. G. Rowan (Der./Ed.) Rethinking the Future: Rethinking Business, Principles, Competition, Control \& Complexity, Leadership, Markets, and the World: 148-163. London, Nicholas Brealey.

Bennis, W. (2007). The challenges of leadership in the modern world: Introduction to the special issue. American Psychologist, 62(1): 2-5.

Bennis, W. ve Nanus, B. (2005). Leaders: The Strategies for Taking Charge. New York: Collins Business Essentials.

Bolman, L. G. ve Deal, T. E. (2011). Leading with Soul: An Uncommon Journey of Spirit. San Francisco: John Wiley \& Sons.

Brown, R. (2016, March 07). How to re-ignite the spark in a disengaged employee. http://www.hrmonline.com.au/section/featured/howto-re-engage-an-employee/ Erişim tarihi 20.08.2018

Byham, T. M. ve Wellins, R. S. (2015). Your First Leadership Job: How Catalyst Leaders Bring Out the Best in Others. Hoboken, New Jersey: Wiley.

Chang, R. (2001). The Passion Plan at Work: Building a Passion Driven Organization. San Francisco: Jossey-Bass.

Churchill, G. A. (1979). A paradigm for developing better measures of marketing constructs. Journal of Marketing Research, 16(1): 6473.

Colan, L. (2014, January 29). 3 ways to spark employee passion. https:/ /www.inc.com/lee-colan/3-ways-to-spark-employeepassion.html Erişim tarihi 20.08.2018 
Daft, R.L. (2003). Management. USA: South Western.

Denning, S. (2014, October 08). Debunking myths about worker passion. https://www.forbes.com/sites/stevedenning/2014/10/08/debun king-myths-about-worker-passion/\#c30b2b08f4bc. Erişim tarihi 30.08.2018

DeRue, D. S. ve Workman, K. M. (2012). Toward a positive and dynamic theory of leadership development. In G. M. Spreitzer \& K. S. Cameron (Eds.). The Oxford handbook of positive organizational scholarship. New York, NY: Oxford University Press.

DeVellis, R. F. (2012). Scale Development: Theory and Applications. ( $^{\text {rd }}$ Ed.) Thousand Oaks, CA: Sage Publications.

Fornell, C. ve Larcker, D.F. (1981). Evaluating structural equation models with unobservable variables and measurement error, Journal of Marketing Research, 18: 39-50.

García-Sierra, R., Fernández-Castro, J. ve Martínez-Zaragoza, F. (2016). Work engagement in nursing: An integrative review of the literature, Journal of Nursing Management, 24(2): 101-111.

Gleeson, B. (2017, March 27). The future of leadership and management in the 21st century organization. https://www.forbes.com/sites/brentgleeson/2017/03/27/thefuture-of-leadership-and-management-in-the-21st-centuryorganization/\#5d60bc82218f Erişim tarihi 03.09.2018

Global Human Capital Trends (2015). Leading in the New World of Work. https://www2.deloitte.com/au/en/pages/humancapital/articles/introduction-human-capital-trends-2015.html Erişim tarihi 25.08.2018

Greenberg, M. (2012, June 19). Five essential skills for leadership in the $21^{\text {st }}$ century. https://www.psychologytoday.com/blog/the-mindfulself-express/201206/ five-essential-skills-leadership-in-the-21stcentury Erişim tarihi 15.08.2018

Hambrick, D. C. ve Mason, P. A. (1984). Upper echelons: The organization as a reflection of its top managers, Academy of Management Review, 9: 193-206.

Hannagan, T. (2002). Mastering Strategic Management. Palgrave Macmillan.

Hair, J. F., Black, W. C., Babin, B. J. ve Anderson, R. E. (2009). Multivariate Data Analysis. (7 ${ }^{\text {th }}$ Ed.) Harlow, UK: Pearson. 
Hinkin, T. R. (1995). A review of scale development practices in the study of organizations, Journal of Management, 21: 967-988.

Hinkin, T. R. (1998). A brief tutorial on the development of measures for use in survey questionnaires, Organizational Research Methods, 1: 104-121.

House, R., Javidan, M. ve Dorfman, P. (2001). Project GLOBE: An Introduction, Applied Psychology, 50(4): 489-505

Hunter, S. T., Bedell-Avers, K. E. ve Mumford, M. D. (2007). The typical leadership study: Assumptions, implications, and potential remedies. The Leadership Quarterly, 18: 435-446.

İlgün Kamanlı, A. (2015). Girişimci yöneticinin işe tutkunluk ve liderlik tarzının çalısanların performans algıları üzerine etkisi. Yayımlanmamış Doktora Tezi. İstanbul: Marmara Üniversitesi Sosyal Bilimler Enstitüsü.

İslamoğlu, G. ve Börü, D. (2007). Politik Davranış Boyutları: Bir Ölçek Geliştirme Çalışması. Akdeniz İIBF Dergisi, 14: 135-153.

Johnson, R. L. ve Morgan, G. B. (2016). Survey Scales: A Guide to Development, Analysis, and Reporting (1st Ed.) New York, NY: The Guilford Press.

Komives, S. R. ve Dugan, J. P. (2010). Contemporary Leadership Theories. In R. Cuoto (Ed.) Political and Civic Leadership: A Reference Handbook (111-119). Los Angeles, CA: Sage Publications.

Landis, J. ve Knoch, G. (1977). The measurement of observer agreement for categorical data. Biometrics, 33: 159-174.

Lipman, V. (2014). 4 tips to motivate the unmotivated. https://www.forbes.com/sites/victorlipman/2014/10/13/4-tipsto-motivate-the-unmotivated/\#6e19f29c735d Erişim tarihi 15.08.2018

Llopis, G. (2014, July 29). Leadership is about enabling the full potential in others.

https:/ /www.forbes.com/sites/glennllopis/2014/07/29/leadershi p-is-about-enabling-the-full-potential-in-others /\#6443d2ab6698 Erişim tarihi 15.08.2018

Lucas, J. R. (1999). The Passionate Organization: Igniting the Fire of Employee Commitment. USA: Amacom Books.

Malone, O. (2004). 101 Leadership Actions for Creating and Managing Virtual Teams. Amherst, MA: HRD Press. 
Mann, A. ve Harter, J. (2016, January 7). The worldwide employee engagement crisis. http://news.gallup.com/businessjournal/188033/worldwideemployee-engagement-crisis.aspx Erişim tarihi 30.08.2018

McShane, S. L. Ve Glinow, M. V. (2005). Organizational Behavior: Emerging Realities for the Workplace Revolution (3rd ed.). NewYork: The McGraw-Hill Companies

Miller, A. (2017, July 05). How to spark passion in your employees. https:// careertrend.com/spark-passion-employees-9354.html Erişim tarihi 30.08.2018

Mostovicz, E.I., Kakabadse, N.K. ve Kakabadse, A. (2009). A dynamic theory of leadership development, Leadership \& Organization Development Journal, 30(6): 563-576.

Netemeyer, R. G., Bearden, W. O. ve Sharma, S. (2003). Scaling Procedures: Issues and Applications. Thousand Oaks, CA: Sage publications.

Newman, D.A. (2003). Longitudinal modeling with randomly and systematically missing data: a simulation of ad hoc, maximum likelihood, and multiple imputation techniques, Organizational Research Methods, 6: 328-362.

Nunnally, J. C. ve Bernstein, I. H. (1994). Psychometric Theory (3rd Ed.) New York, NY, USA: McGraw-Hill.

Patton, M. Q. (2002). Qualitative Research and Evaluation Methods (3 Ed.) Thousand Oaks: CA: Sage.

Popper, M. (2001). Hypnotic Leadership: Leaders, Followers, and the Loss of Self. Westport, Connecticut: Praeger Publishers.

Reisinger, H. (2015, October 27). Five ways to light the fire within our workers. https://blog.jabra.com/five-ways-to-light-the-fire-withinour-workers/ Erişim tarihi 10.08.2018

Riggio, R. E. (2010, March 17). Leadership 101: How leadership has changed in the last generation. https:/ /www.psychologytoday.com/blog/cutting-edgeleadership/201003/leadership-101-how-leadership-has-changedin-the-last-generation Erişim tarihi 20.08.2018

Robins, A. (2017, March 27). Passion For Work Is More Important Than Engagement. https://www.officevibe.com/blog/passion-workimportant-engagement Erişim tarihi 30.09.2019

Rossiter, J. R. (2002), The C-OAR-SE procedure for scale development in 
marketing. International Journal of Research in Marketing, 19(4): 305-335.

Salanova, M., Lorente, M.L., Chambel, M.J. ve Martínez, I.M. (2011) Linking transformational leadership to nurses' extrarole performance: the mediating role of self-efficacy and work engagement. Journal of Advanced Nursing, 67(10): 2256-2266.

Spector, P. E. (1992). Summated Rating Scale Construction: An Introduction. New York, NY: Sage.

Şimşek, H. ve Yıldırım, A. (2013). Sosyal Bilimlerde Nitel Araştırma Yöntemleri. Seçkin Yayıncilık.

Tabachnick, B. G. ve Fidell, L. S. (2013). Using multivariate statistics (6. basi). Boston, MA: Pearson Education.

Teddlie, C. ve Yu, F. (2007). Mixed methods sampling: a typology with examples. Journal of Mixed Methods Research, 1(1): 77-100.

The Ken Blanchard Companies (2009). From Engagement to Work Passion: A deeper understanding of the Employee Work Passion framework. http://www.blanchard.com.tr/media/files/44e1e4db686b-4b91-83dc-8a0ada027ab8.pdf Erişim tarihi 30.09.2019

Trépanier, S., Fernet, C., Austin, S., Forest, J. ve Vallerand, R.J. (2014). Linking job demands and resources to burnout and work engagement: Does passion underlie these differential relationships? Motivation and Emotion, 38(3): 353-366

Vallerand, R. J., Mageau, G. A., Ratelle, C., Leonard, M., Blanchard, C., Koestner, R., Gagne, M. (2003). Les passions de l'ame: on obsessive and harmonious passion. Journal of Personality and Social Psychology, 85: 756-767.

Whitehurst, J. (2015). The Open Organization: Igniting Passion and Performance. Boston: Harvard Business Review Press.

Whitehurst, J. (2016, February 15). How to build a passionate company. https://hbr.org/2016/02/how-to-build-a-passionate-company Erişim tarihi 01.09.2018.

Workforce Purpose Index (2016). Purpose at work. https://cdn.imperative.com/media/public/Global_Purpose_Inde x_2016.pdf Erişim tarihi 30.09.2019

Yurtkoru, S. (2001). The role of leadership in the organizational change process. Yayımlanmamış Doktora Tezi. İstanbul: Marmara Üniversitesi Sosyal Bilimler Enstitüsü. 